\title{
Researchers: Are You Asking the Wrong Questions?
}

\section{Charles Dhanaraj}

\author{
KEYWORDS: Entrepreneurship, Research Methods, \\ Higher Education.
}

\begin{abstract}
Editor's Note: Charles Dhanaraj is the Founding Executive Director of the Translational Research Center at Temple University's Fox School of Business and the H.F. "Gerry" Lenfest Professor of Strategy. He is also Executive Director of the Fox School's Executive Doctorate in Business Administration program.
\end{abstract}

Today typical tenure-track professors spend their time creating data sets and running models, attending conferences hobnobbing with other professors, or in their offices cranking up their research. But the fruits of that research, while it may help the professor achieve tenure, often has very little impact on the people who are the ultimate targets - business executives and entrepreneurs.

Consider that the average business school might spend at least $40 \%$ of its budget on research. How should the school count the payoff? Well, a typical journal article is read by a few hundred academic peers. Yet the millions of executives, small business owners and entrepreneurs engaged in the day-to-day running of their businesses would see little relevance in it. These are the decisionmakers who make a business succeed or fail, and affect its fortunes and those of its stakeholders.

To truly help practicing entrepreneurs run more successful businesses that enrich their communities and encourage economic growth, professors need to stop what one of my respected colleagues terms, "being self-referential," (meaning just to one another) and focus more on what truly benefits the world outside the college.

This means that we need to incorporate "translational science." It's common among medical schools and catching on at business schools, including at Temple University where I teach. While translational science is a relatively new term, many business schools have used the term "engaged scholarship," attributed to Professor Andrew Van de Ven from University of Minnesota.
How can a business school approach a translational science program? There are four steps to it: three steps on the academic side, and the fourth on the industry side. But it all starts with asking ourselves: "Are we asking the right question?"

We can't find that out without engagement. Without engaging with people in the field, you'll have little clue about which questions need to be answered. For example, if you want to do research on mergers and acquisitions, you could approach it by combing through tons of databases, reading what's already been researched and published, running statistical regressions and throwing in a good theory. You might even get a good paper out of it and applause from your peers. But unless you sit down with an executive who is handling these issues for a living, you'll never understand the questions that really merit our top attention. As scholars, as academics with a vantage point of multiple business situations, we may be able to frame the question much more elegantly than any of the practitioners. But, unless you engage, you will not have that insight.

It is sad to see many a researcher investing his or her lifetime writing articles without asking, "Why does this world need this?" Interesting data or elegant empirics can't cover up if that research does not address a substantive question. And to get a sense of the usefulness, engagement with practice is crucial. With the right question, we can pursue it with the rigor that is an academic's strong suit: sound data, good analysis and robust insights.

Asking the right question is the first step. But getting our research to yield actionable insights is the next big step. The second key question is, "Are they actionable?" Sometimes good research can generate an idea, a concept, or an insight that by itself may not be immediately useful, but is indispensable if it is connected with a few other ideas. This is what Ernest Boyer called "application or integration scholarship." 
Often disruptive research needs some applied research to get to actionable insights. But, this is missing in our business schools, partly because this type of inquiry is not recognized as scholarly.

The third part of it is communications. Sadly, most executives can't make sense out of a majority of the articles in top journals. They are not the target readers of our journals, and that's a shame. It's a tragedy that the Journal of Finance does not speak to a chief financial officer; the Strategic Management Journal does not speak to a CEO. We have created a jargon, a language for ourselves that is babel to the outside world. We need to do better. That means writing for the nonacademic world, and going far beyond the paper communication and incorporating podcasts, webcasts, etc. We can and should find new ways to make our important research more accessible to the people who need it most by understanding how they consume information.

Ultimately, translational science is about two things: making sure that our research efforts are directed to the important issues that matter, and getting the insights from our research to the intended targets in an applicable and an understandable manner. If it's a policy audience, it should be readable and actionable by a policy maker. If it's an executive audience, then executives should be able to gain some insights that help them do a better job of managing. If it's a business owner audience, business owners should glean some takeaways that will help their ventures be more successful.

Great research brings prestige to a university, and tenure and other rewards to the researchers themselves. But we need to redefine what "great" means through the lens of relevance and usefulness. Unless we know which questions to ask, gear our research to generating answers that truly benefit business and society, and find effective ways to communicate those insights, we jeopardize our long term future.

Additional Search Terms: Partnerships between colleges and business, partnerships between universities and business, what should I research, best practices 